\title{
PERSPECTIVAL SKEPTICAL THEISM
}

\author{
Jonathan Curtis Rutledge
}

\begin{abstract}
Skeptical theists have paid insufficient attention to non-evidential components of epistemic rationality. I address this lacuna by constructing an alternative perspectivalist understanding of epistemic rationality and defeat that, when applied to skeptical theism, yields a more demanding standard for reasonably affirming the crucial premise of the evidential argument from suffering. The resulting perspectival skeptical theism entails that someone can be justified in believing that gratuitous suffering exists only if they are not subject to closure-of-inquiry defeat; that is, a type of defeat that prevents reasonable belief that $p$ even if $p$ is very probable on an agent's evidence.
\end{abstract}

The strongest versions of the argument from suffering have been primarily cast in an evidential form. ${ }^{1}$ That is, they have been crafted in such a way as to hinge on the mere weighing of evidence. Although this might appear innocuous at first glance, ${ }^{2}$ it is not as innocent as it seems. For the reasonability of believing a proposition (e.g., gratuitous suffering exists) plausibly depends on more than merely evidential matters. It also depends importantly on non-evidential, but still epistemic, factors that can vary significantly from agent to agent. Such factors include, for instance, an agent's degree of epistemic self-trust or the degree of risk they are willing to take on in pursuit of the truth and avoidance of error.

This focus on merely evidential considerations has trickled down to the epistemic assumptions involved in responses to the argument from suffering as well. And nowhere is this more apparent than in the models of skeptical theism found in current literature. Given that skeptical theism aims to undermine the reasonability of believing that there are gratuitous evils, and given further that one's reasonability in believing something depends on more than merely evidential considerations, one would expect skeptical theism to (sometimes) take on more than a merely evidentialist ${ }^{3}$ form.

\footnotetext{
'See, for instance, Rowe, "The Evidential Argument from Evil" and Draper and Dougherty, "Explanation and the Problem of Evil."

${ }^{2}$ After all, what's not to like about arguing something by citing evidence?

"I use "evidentialist" broadly here to include those who think that fit with evidence is at least a necessary condition of rational/justified belief. By "merely evidentialist," then, I refer to anyone who thinks non-evidential factors are irrelevant considerations in the par-
} 
In a previous article ${ }^{4}$ provided the beginnings of a framework for developing just such a version of skeptical theism by suggesting that skeptical theism might be wedded to a perspectivalist account of epistemic rationality. However, this suggestion was made without much by way of further elaboration concerning what such a view might look like in full. It is the purpose of this essay to remove this lacuna by constructing a more robust account of a new perspectival skeptical theism, as well as to highlight the significant contributions such a view makes to the current literature on the argument from suffering.

I begin in $\$ 1$ by reintroducing the basic structure of the argument from suffering and skeptical theism as a response to it. Upon completing this, I briefly turn in $\S 2$ to a distinction between two different types of epistemic undercutting defeaters, namely, evidential defeaters and closure-of-inquiry defeaters; the elaboration of this distinction is necessary for appreciating perspectival skeptical theism's distinctiveness as a version of skeptical theism. Then in $\S 3$ I turn to a case from the cognitive psychology literature involving empirical studies concerning the selection of applicants for admission to medical school. This case is particularly useful for our purposes because it clearly illustrates various ways in which a putative undercutting defeater-i.e., of either the evidential or closure-of-inquiry sort-might be rationally resolved by agents with different epistemic starting points. More specifically, I argue that we can uncover at least six different rational responses to an epistemic defeater provided by the claims of the empirical studies under question. Next, in $\S 4$ we return once more to skeptical theism where I apply what we have learned from the previous two sections. What we again see is that for any agent entertaining the theses characteristic of skeptical theism, there are at least six different rational ways of resolving the putative defeaters such theses present. Finally, in §5 I reflect on various advantages perspectival skeptical theism possesses over alternative forms of skeptical theism and conclude that it should play a significant part in conversations about the argument from suffering moving forward. Let us begin, then, with an overview of the argument from suffering.

\section{The Argument from Suffering and Skeptical Theism}

The best version of the argument from suffering of which I am aware proceeds in two parts, the first of which can be stated in the following deductive fashion ${ }^{5}$ :

ticular case of the argument from suffering, such that in the context of that discussion, fit with evidence is necessary and sufficient for believing in the existence of gratuitous suffering. See Dougherty and Tweedt ("Religious Epistemology," 552) where they discuss my use of "evidentialist" under the label of "Epistemic Evidentialism." For a nice discussion of the various disputes amongst evidentialists concerning how best to construe their view, see the introduction to Dougherty, Evidentialism and Its Discontents.

${ }^{4}$ Rutledge, "Commonsense, Skeptical Theism, and Different Sorts of Closure of Inquiry Defeat."

${ }^{5}$ There are other arguments from suffering to which skeptical theism (and variants of it) may not be straightforwardly relevant. The traditional logical argument does not make 
1. If God exists, then there are no instances of gratuitous suffering.

2. There are instances of gratuitous suffering.

Therefore,

3. God does not exist.

Now, someone might attack premise 1 for a variety of reasons, ${ }^{6}$ but this is neither the most common response nor the response most relevant to our current concerns. Instead, premise 2 bears the brunt of the critical responses historically-speaking since many theists find it difficult at best to believe that anyone could reasonably believe premise 2 .

In support of the second premise, however, those advancing this argument from suffering might appeal to a principle of commonsense epistemology, such as:

Phenomenal Conservatism: If it seems to $\mathrm{S}$ that $\mathrm{p}$, then $\mathrm{S}$ is prima facie justified in believing p. ${ }^{7}$

On the assumption that such a principle is true or rationally endorsed by someone advancing the argument from suffering detailed above, one could appeal to a combination of this epistemic principle and a particular seeming of some bit of suffering as gratuitous to arrive at a justified belief that there are instances of gratuitous suffering. And so long as there are no defeaters that prevent the immediate prima facie justified belief from becoming ultima facie justified, it will be reasonable for that person to affirm it.

It is at this point that skeptical theism becomes relevant, for skeptical theism is fundamentally at least an endorsement of the claim that there is a putative epistemic defeater for those who might otherwise reasonably believe premise 2 of the argument from suffering. That defeater can be stated as follows:

Skeptical Theism (ST): Human agents simply are not in a position to determine how likely or unlikely it is that a given instance of apparently gratuitous evil is actually gratuitous.

To put it simply, skeptical theists affirm both ST and that someone who reasonably believes ST cannot reasonably endorse premise 2 of the evidential argument from suffering. The reason for this is that ST undercuts the connection between the evidence one possesses of gratuitous suf-

use of the concept of gratuitous evil, but rather, evil simpliciter, and since skeptical theism is not relevant to non-gratuitous forms of evil, it is irrelevant as a response to the logical argument (cf. Mackie, "Evil and Omnipotence"). Plausibly, the Humean arguments developed by Draper are likewise immune to skeptical theist responses (though not obviously). For such an argument, see Draper and Dougherty, "Explanation and the Problem of Evil."

${ }^{6}$ See, for instance, the approach taken in van Inwagen, The Problem of Evil.

${ }^{7}$ See Huemer, Skepticism and the Veil of Perception. This principle is also quoted in Rutledge, “Commonsense, Skeptical Theism, and Different Sorts of Closure of Inquiry Defeat," 18. 
fering (i.e., one's seemings) and what that evidence had been previously thought to support. Or at least, this follows provided that one's seeming-states as of gratuitous suffering are the only source of evidence for premise 2 .

From this brief overview of the argument from suffering, however, it is clear that a completed version of skeptical theism requires further elaboration. For the idea of undercutting the connection between one's evidence and what it supports can be spelled out in a number of different ways. And since the goal of this paper is to construct a version of skeptical theism that relies on a perspectivalist theory of epistemic rationality, let us turn to a brief formal discussion of the two fundamental types of epistemic undercutting defeaters involved in such a view.

\section{On Evidential and Closure-of-Inquiry Undercutting Defeaters}

Undercutting defeaters come in at least two varieties, the first and more familiar of which are evidential defeaters. To understand the nature of evidential defeat, let $e$ be one's evidence concerning $p$ whenever the probability of $p$ given $e$ is greater than the probability of $p$ on one's background evidence alone (i.e., $\operatorname{Pr}[p \mid e]>\operatorname{Pr}[p]$ ). Then we can say that $d_{\text {Full }}$ is a full defeater of the evidential support relation ${ }^{8}$ whenever the probability of $p$ given $e \& d_{\text {Full }}$ is equal to the probability of $p$ alone (i.e., $\operatorname{Pr}\left[p \mid e \& d_{\text {Full }}\right]$ $=\operatorname{Pr}[p])$. We can say that $d_{\text {Partial }}$ is a partial evidential support relation defeater whenever the probability of $p$ given $e \& d_{\text {Partial }}$ is greater than the probability of $p$ alone but less than the probability of $p$ given $e$-that is, the following both hold (on the assumption that $e$ is evidence as construed above):

$$
\begin{aligned}
& \text { i. } \operatorname{Pr}\left[p \mid e \& d_{\text {Partial }}\right]<\operatorname{Pr}[p \mid e] \\
& \text { ii. } \operatorname{Pr}\left[p \mid e \& d_{\text {Partial }}\right]>\operatorname{Pr}[p]^{9}
\end{aligned}
$$

The other sort of defeater sometimes introduced during discussions of perspectivalist forms of epistemic rationality is a closure-of-inquiry defeater, of which one would say the following:

\footnotetext{
${ }^{8}$ Let the "evidential support relation" simply name the relation that holds between $e$ and $p$. That is, let it name the is-evidence-for relation. Notice that in the case of $d_{\text {Partial }} e$ and $p$ continue to instantiate the is-evidence-for relation, but the degree of evidential strength is diminished by the defeater. As I conceive of this, there is but one epistemic support relation that admits of degrees in the same way that a single relation of love might admit of degrees. Moreover, I restrict the discussion above to merely undercutting defeaters and leave the question of rebutting defeaters to one side. Rebutting defeaters of the evidential relation between $e$ and $p$ reduce the strength of the support relation by being evidence for $\neg p$. However, undercutters undermine the relation between $e$ and $p$ without being evidence for the negation of $p$. See Pollock, Contemporary Theories of Knowledge and Pollock and Gillies, "Belief Revision and Epistemology." Despite this, it is possible for a defeater to serve as both an undercutting defeater as well as a rebutting defeater at the same time. Thanks for an anonymous referee for bringing the importance of including these points to my attention.
}

${ }^{9}$ Rutledge, "Commonsense, Skeptical Theism, and Different Sorts of Closure of Inquiry Defeat," 22. 
Such defeaters . . . do not affect the evidential support relation at all qua closure of inquiry defeater. Rather, they defeat the reasonability of believing some target proposition on the basis of one's evidence, no matter how strong or compelling the evidence. ${ }^{10}$

Notice that on this account, closure-of-inquiry defeaters do not target the evidential support relation. Rather, they undermine reasonable belief in a proposition, even if the evidence is very compelling. In other words, we can say that whenever $d_{\text {CoI }}$ is merely a closure-of-inquiry defeater, the following will be true:

iii. $\operatorname{Pr}\left[p \mid e \& d_{\text {CoI }}\right]=\operatorname{Pr}[p \mid e]$, and

iv. Even if $\operatorname{Pr}[p \mid e] \approx 1, p$ cannot be reasonably believed.

Before moving onto the question of why closure-of-inquiry defeaters undermine reasonable belief, as indicated in (iv) above, let me be explicit that one and the same proposition might give someone both a closure-of-inquiry defeater and an evidential defeater of some sort. In such a case, what is fundamental to the presence of a closure-of-inquiry defeater is that $p$ cannot be reasonably believed on the basis of the evidence for $p$, whether or not the degree of evidential support remains unchanged. ${ }^{11}$ Thus, (iii) above only holds for closure-of-inquiry defeaters that arise from a proposition that does not also give the agent in question an evidential defeater. When a proposition does give one an evidential defeater, then the truth or falsity of (iv) determines whether the agent under question also has a closure-of-inquiry defeater.

Now that we have distinguished these two types of defeaters, it is worth pressing further the question of why reasonable belief is undermined by closure-of-inquiry defeaters. There are at least two significant contexts worth attending to for our purposes from which closure-of-inquiry defeat might emerge: scenarios in which (i) further evidence gathering activities

${ }^{10}$ Rutledge, "Commonsense, Skeptical Theism, and Different Sorts of Closure of Inquiry Defeat," 24. The name "closure-of-inquiry defeater" might mislead someone into thinking that such defeaters themselves close off inquiry. This is mistaken, for such defeaters make closure of inquiry no longer reasonable. In other words, their presence opens up (or reopens) inquiry rather than closing it off. Thanks for an anonymous referee who suggested the need for clarification.

${ }^{11}$ Consider a case where one's evidence for $p$ is undermined sufficiently to bring the degree of evidential support between $e$ and $p$ to a point at which closure of inquiry is also defeated. In this case, someone might wonder why we need to posit any defeater in addition to the evidential one since, presumably, the reason one can no longer close off inquiry is due to the evidential support falling below some threshold for reasonable belief. I have two responses to this. First, there are cases in which we have closure-of-inquiry defeaters without any evidential defeat, and so, it seems they cannot be merely reduced to each other. Second, if someone were unconvinced by the cases, then they likely have a view denying dualism about the epistemology of belief and the epistemology of degrees of belief. That is, they likely take either belief or degrees of belief to be fundamental in epistemology. See Jackson, "Belief and Credence," where she discusses how belief-first, credence-first, and dualist positions make a significant difference to various areas of contemporary epistemology. 
seem likely to make a significant difference to what one's evidence supports or (ii) one's epistemic self-trust is called into question. ${ }^{12}$

Concerning the latter sort of closure-of-inquiry defeat that is most relevant for our purposes, it is important to note the following: sometimes epistemic defeaters do not undermine the quality of one's evidence, as normally happens in cases involving evidential undercutting defeat. Rather, often epistemic defeaters target our ability to assess that evidence, independently of whether or not it is of good quality. When our ability to assess evidence is targeted, rather than the quality of the evidence we have, then we find ourselves (potentially) in the possession of a closure-of-inquiry defeater. ${ }^{13}$

To understand better how these different considerations might play out, we turn to an actual case involving evidential and closure-of-inquiry defeaters and consider how such defeaters might interact for reasonable individuals confronted by them. This case is especially helpful for thinking practically about how the formal considerations above might look when put in a concrete context involving someone thinking seriously about what to do or think in light of the threat of an undercutting defeater. Once we have applied the evidential and closure-of-inquiry defeater distinction in this first case, we then turn to see how it might be similarly applied to the case of skeptical theism.

\section{Interviewing Candidates for Medical School: Undermining the Quality of Evidence and the Reliable Assessment of Evidence}

In recent years the relevance of certain sorts of heuristics and biases to a theory of rationality has attracted the attention of epistemologists. ${ }^{14}$ While there are a number of different cases that we could consider, the following scenario involving the interviewing of medical school candidates ${ }^{15}$ is especially illuminating:

\footnotetext{
${ }^{12} \mathrm{~A}$ discerning referee has drawn my attention to a combination of a particular theory of evidence and a theory of evidential support that would prevent closure-of-inquiry defeaters from being non-evidential, even if they are not clearly the same thing as a typical run-of-themill undercutter. Suppose that one takes all evidence to be non-factive mental states (e.g., beliefs), a view which, following McCain, Evidentialism and Epistemic Justification, ch. 2, we call "psychologism." Then suppose we understand evidential support in terms of something akin to proper function such that belief $A$ supports $B$ to a degree within the interval $\langle\mathrm{x}, \mathrm{y}\rangle$ if were $S$ to believe $A$ then $S$ would believe $B$ to a degree within the interval $\langle\mathrm{x}, \mathrm{y}\rangle$ (see Plantinga, Warrant and Proper Function, 167-168 for a way of defining the normative component of conditional epistemic probability along the lines I give here for epistemic support). On this combination of views, closure-of-inquiry defeat reduces to a form of evidential defeat. In this paper I presuppose a propositional account of the ontology of evidence, and on such a view, no such reduction occurs. See Williamson, Knowledge and Its Limits and Kvanvig, "Propositionalism and McCain's Evidentialism" for defenses of the position I assume here.

${ }^{13}$ More on closure-of-inquiry defeaters can be found in Kvanvig, Rationality and Reflection, 115-116 and Kvanvig, "Assertion, Knowledge, and Lotteries."

${ }^{14} \mathrm{Cf}$. Kahneman, Thinking, Fast and Slow for examples of such phenomena.

${ }^{15}$ See Dawes, House of Cards for a discussion of these and other similar studies.
} 
In a wide range of studies, short personal interviews, typically one hour, have been proven unhelpful in improving the accuracy of predictions about the future accomplishments or behavior of the interviewees. One of the studies involves medical school admission committees that conducted personal interviews of applicants to supplement statistical and other impersonally gathered data about the applicants (MCAT scores, grade point average, class rank, quality of undergraduate institution, etc.). The task for the committees was to predict future success in medical school as measured by the grades the students would receive... . The conclusion of these studies is that personal interviews do not improve predictions of future accomplishments or behavior. They did not help the interviewers identify who would become successful in medical school (as measured by grades). . . . Indeed, far from improving predictive performance, the interviews actually worsened the accuracy of the predictions made. ${ }^{16}$

The findings of these studies is not favorable for the continued practice of interviewing potential medical school candidates. For clearly these interviews, when included in the assessment of an applicant, have in the past inhibited medical schools from achieving their goal of selecting the candidates who would be most successful. ${ }^{17}$ Now, suppose that you were required by your superior to conduct one-hour interviews for potential medical school students and that you learned of the studies described above only after conducting the interviews. Despite this, your supervisor has granted you permission to decide how to factor your intuitions concerning each candidate's potential into your overall assessment of them. ${ }^{18}$ It is helpful when thinking about a noetic state undergoing this progression to represent it as constituted by three basic logical steps: (i) Defeater Admission, (ii) Determination of the Defeater-Type, and (iii) Defeater Resolution. We consider these three steps in logical sequence.

First, consider the two different defeaters to which the empirical studies concerning personal medical school interviews might give rise. In light of those studies, one might entertain either the proposition that the evidence one gains through personal interviews is of a bad quality or the proposition that one's ability to gather and assess evidence gained through personal interviews is unreliable. ${ }^{19}$ Notice that both of these propositions would be undercutting

${ }^{16}$ Foley, Intellectual Trust in Oneself and Others, 55-56.

${ }^{17}$ The actual goal of medical schools is, hopefully, much more complicated than what I've stated here. However, these complications are irrelevant to the example as I am employing it, so I ignore them throughout.

${ }^{18}$ Caveat: someone might think that significant self-monitoring might allow an interviewer to reasonably continue to count her intuitions concerning candidates as evidence of future success. Foley (Intellectual Trust, 63-76) offers some helpful reflections on why this is unlikely. However, we can avoid a digression regarding the impossibility of self-monitoring by simply stipulating it in this case.

${ }^{19}$ Notice that here I have introduced a case where the two propositions that serve as undercutting defeaters specify whether the difficulties with the evidence are in the evidence or in the assessment of the evidence. The proposition in question, however, may not be so specific. That higher-order proposition might, for instance, simply state that something about one's first-order evidence is a problem (e.g., that there is a problem with using the evidence 
defeaters if believed by an interviewer, but what is undermined by the two propositions is different. In the former case, the evidence is undermined because it is identified as plausibly misleading. In the latter case, one's ability to gather and evaluate evidence is undermined, not the evidence itself. ${ }^{20}$ In other words, one is faced with either a putative evidential defeater or a putative closure-of-inquiry defeater (or perhaps even both).

The point of Defeater Admission comes as a result of the platitude that we shouldn't believe everything we hear, and in particular, not every putative defeater one entertains need be believed. Whether or not I believe the propositional defeater under question depends on what else I believe, my epistemic risk profile, ${ }^{21}$ my degree of epistemic self-trust, ${ }^{22}$ what I make of the evidence I have received, and so on. To apply this to our current scenario concerning medical school candidate interviews, suppose that I have a justified belief that any empirical studies concerning my reliability in assessing the evidence gathered by means of personal interviews (or the quality of the evidence itself) are complete hogwash. ${ }^{23}$ We might call such a belief, following Plantinga, ${ }^{24}$ a "defeater-deflector." Maintaining such a belief would, if I am consistent, preclude my also believing the putative defeaters of the empirical studies. Thus, before I even begin to consider the defeating potential of any putative defeater, that defeater must first avoid deflection by relevant beliefs I already possess. ${ }^{25}$

Let us suppose for the sake of continuing with this thought experiment that at least one of the putative defeaters has avoided deflection. Thus, the first logical step in the process of defeat has concluded and we begin the second step; namely, Determination of the Defeater-Type. At the beginning

one has for believing the target proposition) without specifying whether the problem is one where the evidence is misleading or one's ability to assess it is somehow compromised. In cases where an insufficiently specific proposition is in play, then the same proposition could give someone both an evidential defeater and a closure-of-inquiry defeater.

${ }^{20} \mathrm{And}$ of course, after reflecting on these empirical studies we might come to think that both of these defeaters are true, in which case, both our reliability in gathering and assessing evidence and the evidence itself will be undermined.

${ }^{21}$ See, for instance, Riggs, "Balancing Our Epistemic Goals"; Riggs, "Epistemic Risk and Relativism"; and Kvanvig, Rationality and Reflection, chapter 5.

${ }^{22}$ For the best work on the notion and import of epistemic self-trust, see Foley, Intellectual Trust and Zagzebski, Epistemic Authority.

${ }^{23}$ Someone might worry about ever justifying such a belief, but since we're dealing with a stipulated example, let us suppose that God has infallibly communicated this proposition to me.

${ }^{24}$ Plantinga, "Reply to Beilby's Cohorts," 223-225 and further discussion of defeater-deflectors in Moon, "Debunking Morality," 210-212. The difference between a defeater-defeater and defeater-deflector is this: in the former case, there is a belief that has functioned as a defeater which is itself the object of defeat by some new belief. In the latter, defeater-deflector case, the proposition doing the deflecting prevents a defeater from arising in the first place.

${ }^{25}$ It is worth noting that even if I do have what could be a defeater-deflector, I might trust that deflector-belief less than I trust the putative defeater (perhaps due to the source of the defeater). Thus, the presence of beliefs that are structurally defeater-deflectors does not prevent defeat in every case. The point, however, is that sometimes such beliefs do prevent defeater admission, and sometimes they do so in accordance with reflective rationality. 
of this second step, then, we are in a position to determine whether the defeater or defeaters which we have admitted into our noetic system are either evidential defeaters (i.e., one which is either partial or full) or closure-of-inquiry defeaters. The way in which this step proceeds, however, is fairly complicated. In order to bring these complications to the surface, in what follows we survey the various combinations of defeater-types along with their correlative Defeater-Resolutions (i.e., step 3).

We have already seen in our discussion of defeater-deflectors that other beliefs are relevant to the admission of a defeater into our noetic system. At this second step, in which we sort out the kind of defeater with which we are dealing, other epistemic factors again become relevant to what might happen. Let us consider five different ways in which rational reflection might play out for the medical school interviews case during this sorting phase. ${ }^{26}$ That is, let us consider what kind of reflection might lead an agent to admit either a closure-of-inquiry defeater, an evidential defeater, or both.

Recall that in our thought experiment, you have already interviewed potential medical school candidates, and thus, you have evidence concerning who the best candidate is based on those interviews as its source. Moreover, prior to considering the implications of these empirical studies, let us stipulate that you had determined that Polly was probably the best medical school candidate. And now, when you hear these studies, you reason as follows:

Wow, it seems like these studies could call into question either the status of the evidence I have gathered from the interviews or my ability to assess that evidence (or both). However, when I reflect on this more carefully, I'm not sure why anyone would think that my evidence is problematic. After all, I simply gathered more information about each candidate in a particular setting. So my evidence doesn't seem to be undermined. Despite this, given that I and all other members of my kind are highly fallible in tracking what this evidence actually connects to, perhaps I should keep my inquiry open until I can either gather more evidence that sufficiently confirms what I already take my current evidence to imply or find a further reason to disregard the findings of these studies that are undermining the trust I have in myself to assess the evidence at hand.

This line of reasoning reflects the noetic system of a person dealing with a closure-of-inquiry defeater, for they do not change their assessment of the evidence they have gathered. Instead, they simply withhold belief in the proposition supported by their evidence until closure of inquiry reacquires rational status.

${ }^{26}$ Although, I should flag that in the end, we actually have six such cases because of the possibility that someone might not admit the putative defeaters into their noetic state to begin with. 
But there are other ways of sorting these putative defeaters. For instance, an agent might take the studies to render the evidence gathered via personal interviews of medical school candidates as merely projective evidence. Such an individual would understand the empirical studies to show that in such interviews we see what we want to see rather than what is actually there. The appropriate response to such information is the same as the appropriate response to learning that the map one is following to Old Faithful in Yellowstone National Park is an outdated map with an incorrectly labeled location for Old Faithful. One would simply throw out the map in such a situation, and in the case of the interviews, one would simply throw out the evidence one has gathered about the candidates in the course of the interviews. And importantly, after one's evidence has been fully undermined in this way, one need not reopen inquiry, but rather, once the change in evidential evaluations has taken place, inquiry can be closed. In other words, this describes someone who takes the empirical studies to provide a fully undercutting evidential defeater without also acquiring a defeater for closure of inquiry.

Yet suppose we have someone who similarly understands the evidence gathered via personal interviews to be in some important sense projective. However, suppose further that they think this is only partially the case. Some of the evidence they have gathered, let's suppose, is not, to their lights, misleading. Such a person might then recalibrate the degree of strength accorded the evidence of personal interviews-perhaps only counting it to a slight degree-without disregarding the evidence in its entirety. In such a case, then, this person has acquired a partially undercutting evidential defeater.

Might such a person also acquire a closure-of-inquiry defeater? Perhaps. Whether or not they would acquire such a defeater, for instance, might depend on how epistemically cautious they are. Or rather, it might depend on the makeup of their epistemic risk profile. Consider the following case from Thomas Kelly that illustrates this point well:

Suppose that the evidence available to me is just barely sufficient to justify my belief that it will rain tomorrow: if the evidence was even slightly weaker than it is, then I would be unjustified in thinking that it will rain. Suppose further that you have the same evidence but are slightly more cautious than I am, and so do not yet believe that it will rain tomorrow. It is not that you are dogmatically averse to concluding that it will rain; indeed, we can suppose that if the evidence for rain gets even slightly stronger, then you too will take up the relevant belief. Is there some guarantee, given what has been said so far, that you are being less reasonable than I am?-I doubt it. ${ }^{27}$

In our case, take two individuals, Judah and Peri, who respond to the empirical studies by recalibrating the degree of strength they accord to the

\footnotetext{
${ }^{27}$ Kelly, "Peer Disagreement and Higher-Order Evidence," 120n9 (quoted in Kvanvig, Rationality and Reflection, 140, to illustrate a similar point concerning rationality).
} 
evidence of the interviews in precisely the same way. However, suppose that Judah is slightly more cautious than Peri, and as a result of recalibrating his assessment of the evidence's strength decides to reopen inquiry concerning the identity of the best medical school candidate. Peri, however, still finds the evidence sufficiently compelling after recalibration to conclude that Polly is the best candidate. In this instance, then, Peri has only acquired a partially undercutting evidential defeater while Judah has acquired in addition a defeater for closure of inquiry.

So, it is not too difficult to imagine how someone might reasonably acquire a partially undercutting evidential defeater alongside a closure-of-inquiry defeater. But might someone who has a fully undercutting evidential defeater also acquire a closure-of-inquiry defeater? This combination could be reasonable as well. Suppose that you acquire a fully undercutting evidential defeater as described earlier, but further suppose that you exhibit some doubt about your belief that the evidence gathered during the personal interviews was actually projective. Indeed, you think that the prospect of gathering more evidence about the empirical studies themselves might reasonably lead to a defeater-defeater. That is, you think further evidence gathering might provide evidence which would undermine the trustworthiness of the empirical studies and further cancel out the evidential defeater you have acquired from those studies. In such a case, learning of the studies undermines the evidence you have gathered via personal interviews, but it also provides a reason to reopen an investigation concerning the best way to proceed in gathering evidence. Thus, it seems possible, though admittedly unlikely, that someone might rationally acquire both a fully undercutting evidential defeater and a closure-of-inquiry defeater on the basis of these interviews. This concludes our survey of the different rational reactions one might have to learning of the contents of these empirical studies.

What I have just done, then, is provide six different cases of individuals faced with putative evidential and closure-of-inquiry defeaters. Each case was described differently to illustrate how differences in one's epistemic machinery (e.g., epistemic risk profile, degree of self-trust, etc.) make possible different rational reactions to the same putative defeaters. Those different reactions included (1) denying admission to either defeater full stop, or acquiring one of (2) a partially undercutting evidential defeater, (3) a fully undercutting evidential defeater, (4) a closure-of-inquiry defeater, (5) both a partially undercutting evidential defeater and a closure-of-inquiry defeater, or (6) both a fully undercutting evidential defeater and a closure-of-inquiry defeater. ${ }^{28}$

In the next section, we apply what we have learned to the question of skeptical theism. As becomes clear, changes to one's theory of epistemic

\footnotetext{
${ }^{28}$ Lest a reader object to this presentation of six options with a worry of the form, "What about option $x$ ?," for the purposes of this essay I am not committing to any claim that the six options given are exhaustive of the possibilities.
} 
defeat, including but not limited to the addition of closure-of-inquiry defeaters, have significant implications for the merits of skeptical theism as a response to the argument of evil. We shall see, in fact, that there is a plurality of reasonable responses to skeptical theism, all of which depend on the epistemic character of the agent assessing the evidence of suffering.

\section{Perspectival Skeptical Theism: Rational Optionality and Epistemic Defeat in the Face of Evil}

It is now time to apply the distinction between evidential and closure-of-inquiry defeaters, along with what we have gleaned from the various ways in which such defeaters might be resolved, to the case of skeptical theism and the argument from suffering. Recall the original statement of skeptical theism from $\S 1$ :

Skeptical Theism (ST): human agents simply are not in a position to determine how likely or unlikely it is that a given instance of apparently gratuitous evil is actually gratuitous.

There are, it seems to me, two different putative defeaters that skeptical theism might generate for a given agent who is entertaining ST. This is due to the fact that there are two different ways to explain why human agents are unreliable in the way ST suggests. First, an agent might think that ST calls into question the quality of the evidence for gratuitous suffering of which she is in possession..$^{29}$ Second, however, an agent might alternatively think that ST undermines her reliability in assessing the evidence she has. In other words, skeptical theism, like the earlier case involving the interviewing of medical school candidates, includes the potential for two different undercutting defeaters: one aptly described as evidential and the other as closure-of-inquiry.

So, the case of ST parallels the medical school candidate interviews case, and the parallels are these: (a) both cases concern the gathering and assessment of evidence in a particular domain, and (b) both cases threaten either an evidential defeater (with, presumably, either partial or full defeating power) or a closure-of-inquiry defeater. Moreover, the variables involved in determining the possible rational responses to the putative defeaters involved in the medical school interviews case were not variables specific to that case. Rather, they were variables that could in principle apply to any parallel instance of epistemic defeat. But the case of ST is a parallel instance of such epistemic defeat. Thus, the six rational

\footnotetext{
${ }^{29}$ It is worth keeping in mind that, with respect to our agent's evidence gathering practices, she might not be doing anything epistemically wrong in gathering evidence. She might simply be stuck in a situation with respect to the evidence of gratuitous suffering analogous to the situation facing the denizens of evil demon worlds. That is, she might gather evidence perfectly well. The problem will merely lie in the fact that all the evidence she responsibly gathers is fundamentally misleading. That is, in such situations it is the evidence that is the problem rather than the agent.
} 
reactions to the putative defeaters found in the medical school interviews case should also be found in the case of ST.

What do we get when we consider the six different types of rational reactions involved in the case of ST? We again have the following possibilities: (1) denying admission to ST as a defeater full stop or acquiring ST as one of the following -(2) a partially undercutting evidential defeater, (3) a fully undercutting evidential defeater, (4) a closure-of-inquiry defeater, (5) both a partially undercutting evidential defeater and a closure-of-inquiry defeater, or (6) both a fully undercutting evidential defeater and a closure-of-inquiry defeater.

Let us consider the upshot of this theory of defeat, then, for ST. According to option 1, it can be rational for someone to dismiss ST entirely. That is, in some cases, this employment of ST allows that someone can rationally endorse premise 2 of the argument from suffering after entertaining the possibility of ST (i.e., as in option 1 ). However, this employment of ST also allows that someone might be forced, on pain of irrationality, to entirely withdraw belief in premise 2 (i.e., as in options 3, 4, 5, and 6). This is true of the final three options because of the presence of closure-of-inquiry defeat, which prohibits reasonable belief even in the face of very strong evidence. Furthermore, this is true in the case of option 3 in virtue of the fact that one's seemings as of gratuitous suffering are (or, at least, very likely are) the most significant source of evidence that there is gratuitous suffering. It follows from this that if that evidence is fully undermined and we assume that no other source of such evidence is in play, then one will possess no evidence in favor of the existence of gratuitous suffering. ${ }^{30}$ Thus, it seems quite unlikely that someone finding themselves characterized by option 3 would be in an epistemically favorable position with respect to affirming that gratuitous suffering exists. When it comes to option 2, whether or not an agent remains on-balance justified in affirming that gratuitous suffering exists (i.e., after entertaining and resolving ST as a partially undercutting evidential defeater) depends on the degree of recalibration required by that agent's noetic system and the other epistemic standards by which she can be represented (e.g., epistemic risk profile, epistemic self-trust, etc.). Such an agent might be rational in retaining a belief that gratuitous suffering exists (i.e., a belief in premise 2), but to know whether this is the case requires us to know more about that agent. In other words, mere knowledge of the propositions composing that agent's evidence will be insufficient to further know whether that agent is justified in affirming that gratuitous suffering exists.

\footnotetext{
${ }^{30}$ Of course, one might, for instance, have a friend who is one's epistemic superior and is also supremely trustworthy. Perhaps that friend also finds the evidential argument from evil compelling and provides testimonial evidence. In that case, the particular evidential support relation targeted by ST would not affect all the relevant evidence since some of the relevant evidence is testimonial (i.e., not gathered from attending to one's seemings). I bracket out this and similar sources of evidence in subsequent discussion.
} 


\section{Reflection on the Benefits of Perspectival Skeptical Theism}

The preceding story concerning how the epistemic defeater(s) involved in ST might rationally play out partly constitutes what I have been calling perspectival skeptical theism. Endorsing such a view of epistemic rationality, however, is not itself sufficient to be a perspectival skeptical theist, for endorsing that view of defeat is compatible with also thinking that ST never serves as a defeater for anyone. It would indeed be an odd form of skeptical theism that denied ST defeated anything. Thus, in addition, perspectival skeptical theism affirms that when it comes to cases that are rightly characterized by the no defeat option (i.e., where the agent under consideration does not acquire a defeater when reflecting on ST), the agents involved likely suffer from a form of epistemic deficiency different from the egocentric rationality of particular concern to perspectivalists. ${ }^{31}$ Perhaps such agents possess undue intellectual arrogance or perhaps they are motivated by something other than truth. The reason for the epistemic deficiency would vary from case to case, but the fundamental point of the perspectival skeptical theist would be that (i) there are multiple dimensions of epistemic evaluation of which egocentric rationality is but one (though by no means an unimportant one), and (ii) in no-defeat cases of agents entertaining ST, rationality in a broader sense than the egocentric one has been undermined on some epistemically relevant basis.

Before concluding, it is worth briefly reflecting on why someone might be inclined to adopt perspectival skeptical theism over the more traditional variants of skeptical theism. Consider the following from a hypothetical objector. "So the idea of perspectival skeptical theism is that there is this special type of defeater, a closure-of-inquiry defeater, that someone might acquire for the proposition that there are gratuitous evils. Why might someone acquire this defeater? Well, they might do so in virtue of the sorts of considerations routinely given in support of ST (e.g., non-representativeness of evidence, analogical reasoning, etc.). In that case, then, what's so remarkable about this special closure-of-inquiry defeater? The answer seems to be that closure-of-inquiry defeaters, once acquired, prevent an agent from reasonably believing the proposition in question even if the evidential support of that proposition has not been undercut by the defeater. Indeed, even if the degree of evidential support is very high between the agent's evidence and target proposition, reasonable belief is still undermined. If this is right (and it is), then here's my worry: this is a strange version of ST because it seems to imply that the atheist wins the day. Evidential arguments from suffering typically only aim to establish that atheism is probable. But perspectival skeptical theism

\footnotetext{
${ }^{31}$ I say "likely" since the conceptual space will remain, for a consistent perspectivalist, involving someone who scores well on all dimensions of epistemic rationality (i.e., they have a reasonable degree of intellectual virtue, are motivated by truth and not wish-fulfillment or something similar, etc.) but is in the unfortunate situation of just being wrong. Such a situation is analogous to an evil demon case where epistemic justification suffers a disconnect from alethic justification.
} 
seems to imply that even if ST is true, atheism may remain probable! As a result, closure-of-inquiry defeat seems to add little or no support to the skeptical theist's aims." ${ }^{32}$

There are several things to say in response to this objection. First, the last sentence of the objection presupposes that skeptical theists have some sort of common goal. Perhaps this type of objector assumes that all skeptical theists are theists (a reasonable mistake given the misleading name with which the position has been christened). ${ }^{33}$ If that were true, then perhaps the common goal of all skeptical theists could reasonably be identified as the apologetic task of defending theism against all possibility of attack. But this goal is not my goal. I am interested in the argument and a proper understanding of the mechanics of epistemic defeat involved when assessing the argument from the first-person perspective. Thus, if the perspectivalist construal of epistemic defeat is correct and if the objector is right that perspectival skeptical theism allows atheism to win the day, then I am satisfied. For in that scenario, we have a better understanding of the argument as well as the proper place for ST (i.e., even if theism is undermined).

Even so, is it really correct to characterize someone in possession of a closure-of-inquiry defeater as "winning the day," even if their evidence continues to support some target proposition (e.g., that there are gratuitous evils)? Perspectival skeptical theism contends that in addition to sufficient supporting evidence for a proposition, someone can "win the day" only if their evidence is not undermined by a closure-of-inquiry defeater which calls into question the reliability of that evidence or the agent's evaluation of the evidence. To say that someone in this situation has "won the day" seems odd, to say the least. Witness the following sorts of bizarre conclusions as parodies of this sort of objection:

Pink elephants probably exist. I see them everywhere! Granted, I took a hallucinogen this morning, so my evidence is probably systemically misleading. Nevertheless, I am glad to know my argument from I see a bunch of pink elephants to the claim that they probably exist is supported by my evidence.

Polly is probably the best medical school candidate. After all, she nailed the personal interview! Now, I know that those empirical studies strongly undermine the reliability of my intuitions based on that interview, so I won't conclude that Polly is the best candidate. In fact, it would be an epistemic mistake. That is, it would be unreasonable. Nevertheless, I am glad to know that she is probably the best candidate based on my (probably unreliable) evidence.

${ }^{32} \mathrm{I}$ owe this objection to an anonymous referee. Indeed, I have met this objection independently on a number of occasions, which is why I am addressing it in the main text.

${ }^{33}$ The unfortunate-naming observation of skeptical theism has been made by others. See, for instance, Daniel Howard-Snyder, "Epistemic Humility, Arguments from Evil, and Moral Skepticism," 17-18. 
Is Alex guilty of murder? Well, all the evidence seems to point that way, so he's probably guilty. Of course, Alex's defense attorney made a pretty strong case that Alex had been framed, in which case the evidence strongly supports his guilt in a fundamentally misleading way. But at least we know he's guilty on the basis of this potentially misleading evidence. Perhaps that's all we on the jury should care about.

Suppose that the above examples characterize the epistemic situation of someone assessing the merit of the argument from suffering. If so, then I contend that they have further work to do. For the fact that atheism is probable on their evidence doesn't seem significant enough to render "winning the day" an apt description of them. Or to put it another way, "winning the day" is an apt description of them only if it is also an apt description of the three agents described in the three above examples. Unfortunately for the objector, it's clearly not.

Having set aside the above objection, then, are there any positive reasons for endorsing perspectival skeptical theism? That is, does it have any significant advantages over other forms of ST?

Indeed, there are several advantages. First, philosophers residing on both sides of the theistic/atheistic divide understand the strong inclination to believe both of the following propositions; namely, (i) that events like the Holocaust very strongly seem to include gratuitous suffering and (ii) human agents are not reliably able to track all the possible goods, evils, and entailment relations between them, the tracking of which is needed to determine whether an evil is gratuitous. ${ }^{34}$ Any account of rationality should, I think, be able to explain the intuitive pull of these propositions while also allowing that an agent might reject one or the other intuition without giving up their claim to rationality. That is, a strong intuition in support of epistemic permissivism ${ }^{35}$ characterizes this debate, and perspectival skeptical theism provides the epistemic foundations for preserving it.

Second, although perspectival skeptical theism allows that someone might be reflectively rational in dismissing ST as a defeater in its entiretyand thereby leaves the argument from suffering rationally compelling for at least some possible agents - it also makes affirming the argument from suffering more difficult. Many philosophers either explicitly or implicitly betray a tendency to assume that the weighing of evidence is all that fundamentally matters when assessing the argument from suffering, ${ }^{36}$ but the perspectival skeptical theist points out that often other epistemic factors

\footnotetext{
${ }^{34}$ This is akin to the construal of skeptical theism found in Michael Bergmann's version of skeptical theism. See, for instance, Bergmann, "Commonsense Sceptical Theism," 11-12.

${ }^{35}$ For an excellent and brief recent discussion of permissivism, see Kelly, "Evidence Can Be Permissive."

${ }^{36}$ See for instance, Matheson, "Phenomenal Conservatism and Skeptical Theism"; Dougherty, "Phenomenal Conservatism, Skeptical Theism, and Probabilistic Reasoning"; Wykstra, "The Humean Obstacle to Evidential Arguments from Suffering," 148; van Inwagen, "The Problem of Evil, the Problem of Air, and the Problem of Silence," 163, 171; and Bergmann, "Commonsense Scepticism Theism," 23-24.
} 
are relevant (e.g., epistemic risk profiles, degrees of epistemic self-trust, etc.) to an assessment of the argument. It follows from these considerations that even if one determines that the evidence in one's possession strongly confirms that gratuitous suffering exists, one may yet remain unable to reasonably believe the proposition confirmed by one's evidence. That is, until one has gathered sufficient evidence and garnered a sufficient degree of epistemic self-trust to render closure of inquiry appropriate, ${ }^{37}$ belief that there are gratuitous evils will remain rationally inappropriate.

Third, ST has in various places been saddled with concerns that employing skepticism as a response to the argument from suffering precludes the further employment of defenses or theodicies in response to the same argument. Because it includes the possibility of closure-of-inquiry defeat, however, perspectival skeptical theism offers an interesting way out of these concerns. ${ }^{38}$

Suppose that someone, Sandy, acquires a closure-of-inquiry defeater in virtue of having a particular degree of epistemic risk aversion. That is, suppose that Sandy, as a matter of policy when considering subjects insufficiently relevant to everyday life, refuses to affirm a proposition unless she assigns a credence of at least .95 to the proposition. Let the proposition in question be there are gratuitous evils. Prior to considering theodical arguments, Sandy assigns a credence of .96 to there are gratuitous evils. Because of her policy of affirming propositions with a credence of at least .95, she affirms there are gratuitous evils. Suppose she then considers the free-will defense for the first time, and it seems to her that the probability of there are gratuitous evils given her assessment of the free-will defense becomes .94. As a result of considering the free-will defense, the credence she assigns to the proposition that there are gratuitous evils has fallen below the egocentrically-determined threshold for reasonable belief. As a result, she acquires a closure-of-inquiry defeater for the reliability of her evidence that there are gratuitous evils in a way that is perfectly consistent with considering the impact of defenses and theodicies on the evidence of suffering in her possession. ${ }^{39}$

There are other measures by which a philosophical position might be evaluated. Accordingly, I do not intend to claim that the three advantages cited above decisively favor perspectival skeptical theism over its more traditional rivals. Nevertheless, the advantages cited-i.e., its fit with epistemic permissivism, additional requirements for endorsing the argument

\footnotetext{
${ }^{37}$ Rutledge, "Commonsense, Skeptical Theism, and Different Sorts of Closure of Inquiry Defeat," 25-30.

${ }^{38}$ See also Michael Murray, Nature Red in Tooth and Claw, 37-40 for a way of thinking about how traditional forms of ST might allow for considering the merits of theodicies or defenses.

${ }^{39}$ Similar points could be made to explain how the employment of natural theology might be compatible with perspectivalist forms of ST. See, for instance, Wilks, who articulates the worry that ST and natural theology do not fit well together: "The [skeptical theist] rationale that discounts the problem of evil should be applied with equal force to any form of the design argument which appeals to the presence of goods" ("The Global Skepticism Objection to Skeptical Theism," 460).
} 
from suffering, and compatibility with assessing the strength of various theodicies-offer a significant change to the thrust of the debate and can refocus the discussion of skeptical theism on epistemic foundations which too often go critically unexamined.

\section{Conclusion}

In this article, I constructed a new form of skeptical theism, perspectival skeptical theism, modeled as a combination of a standard skeptical theist's thesis, ST, with a perspectivalist form of epistemic rationality and defeat. After distinguishing between evidential and closure-of-inquiry defeaters, I considered how such defeaters might differently interact with epistemically varied agents. I identified six possible rational outcomes of agents faced with putative epistemic undercutting defeat spawning from the results of a study conducted on the trustworthiness of medical school interviews as sources of evidence for the best future medical school students. Next, I showed how the defeaters emerging from the medical school case could be seen as parallel to the defeaters involved in an agent's entertaining of ST. By drawing out the parallels, I arrived at a description of perspectival skeptical theism and briefly reflected on its advantages over alternative interpretations of the epistemic implications of ST. Those advantages, though not alone decisive, demonstrate that perspectival skeptical theism both holds much promise as a way of progressing the quality of debate surrounding the argument from suffering and deserves more attention moving forward..$^{40}$

University of St Andrews

\section{References}

Bergmann, Michael. 2012. "Commonsense Skeptical Theism." In Reason, Metaphysics, and Mind: New Essays on the Philosophy of Alvin Plantinga, edited by Kelly James Clark and Michael C. Rea (Oxford University Press), 9-30. https://doi.org/10.1093/acprof:oso/9780199766864.003.0002

Dawes, Robyn M. 1994. House of Cards: Psychology and Psychotherapy Built on Myth (The Free Press). https://doi.org/10.1097/00005053-199509000-00011

Dougherty, Trent. 2011. Evidentialism and Its Discontents (Oxford University Press). https://doi.org/10.1093/acprof:oso/9780199563500.001.0001

\footnotetext{
${ }^{40}$ I would like to thank Joshua Cockayne, Kevin Diller, Mark Murphy, Kevin Nordby, Stephanie Nicole Nordby, Alan Torrance, Linda Zagzebski, and two anonymous referees for helpful discussions and feedback over the material in this article. I would also like to thank the Templeton Religion Trust for generous funding which provided the time and space necessary to commit the ideas of this paper to their current form.
} 
Dougherty, Trent. 2014. "Phenomenal Conservatism, Skeptical Theism, and Probabilistic Reasoning." In Skeptical Theism: New Essays, edited by Trent Dougherty and Justin P. McBrayer (Oxford University Press), 21-31. https://doi.org/10.1093/acprof:oso/9780199661183.003.0002

Dougherty, Trent, and Chris Tweedt. 2015. "Religious Epistemology." Philosophy Compass 108: 547-559. https://doi.org/10.1111/phc3.12185

Draper, Paul, and Trent Dougherty. 2014. "Explanation and the Problem of Evil." In The Blackwell Companion to the Problem of Evil, edited by Justin P. McBrayer and Daniel Howard-Snyder (John Wiley and Sons), 67-82. https://doi.org/10.1002/9781118608005.ch5

Foley, Richard. 2001. Intellectual Trust in Oneself and Others (Cambridge University Press). https://doi.org/10.1017/CBO9780511498923

Howard-Snyder, Daniel. 2010. "Epistemic Humility, Arguments From Evil, and Moral Skepticism." In Oxford Studies in Philosophy of Religion, Vol. 2, edited by Jonathan L. Kvanvig (Oxford University Press), 17-57.

Huemer, Michael. 2001. Skepticism and the Veil of Perception (Rowman and Littlefield).

Jackson, Elizabeth Grace. Forthcoming. "Belief and Credence: Why the Attitude-type Matters." Philosophical Studies.

Kahneman, Daniel. 2011. Thinking, Fast and Slow (Penguin Group).

Kelly, Thomas. 2009. "Peer Disagreement and Higher-Order Evidence." In Disagreement, edited by Richard Feldman and Ted A. Warfield (Oxford University Press), 111-174.

Kelly, Thomas. 2013. "Evidence Can Be Permissive." In Contemporary Debates in Epistemology (2nd Edition), edited by Matthias Steup, John Turri, and Ernest Sosa (Wiley), 298-311.

https://doi.org/10.1093/acprof:oso/9780199226078.003.0007

Kvanvig, Jonathan L. 2009. “Assertion, Knowledge, and Lotteries.” In Williamson on Knowledge, edited by Duncan Pritchard and Patrick Greenough (Oxford University Press), 140-160.

https://doi.org/10.1093/acprof:oso/9780199287512.003.0010

Kvanvig, Jonathan L. 2014. Rationality and Reflection: How to Think About What to Think (Oxford University Press).

https://doi.org/10.1093/acprof:oso/9780198716419.001.0001

Kvanvig, Jonathan L. 2018. "Propositionalism and McCain's Evidentialism." In Believing in Accordance with the Evidence: New Essays on Evidentialism, edited by Kevin McCain (Springer Publications), 345-357.

https://doi.org/10.1007/978-3-319-95993-1_20

Mackie, J. L. 1955. “Evil and Omnipotence.” Mind 64: 200-212. https://doi.org/10.1093/mind/LXIV.254.200

Matheson, Jonathan. 2014. "Phenomenal Conservatism and Skeptical Theism." In Skeptical Theism: New Essays, edited by Trent Dougherty and Justin P. McBrayer (Oxford University Press), 3-20. https://doi.org/10.1093/acprof:oso/9780199661183.003.0001

McCain, Kevin. 2014. Evidentialism and Epistemic Justification (Routledge Publishing). https://doi.org/10.4324/9781315882390 
Moon, Andrew. 2017. "Debunking Morality: Lessons from the EAAN Literature." Pacific Philosophical Quarterly 98: 208-226. https://doi.org/10.1111/papq.12165

Murray, Michael J. 2008. Nature Red in Tooth and Claw (Oxford University Press). https://doi.org/10.1093/acprof:oso/9780199237272.001.0001

Plantinga, Alvin. 1993. Warrant and Proper Function (Oxford University Press). https://doi.org/10.1093/0195078640.001.0001

Plantinga, Alvin. 1996. "Epistemic Probability and Evil." In The Evidential Argument from Evil, edited by Daniel Howard-Snyder (Indiana University Press), 69-96.

Plantinga, Alvin. 2002. "Reply to Beilby's Cohorts." In Naturalism Defeated? Essays on Plantinga's Evolutionary Argument Against Naturalism, edited by James Beilby (Cornell University Press), 204-275.

Pollock, John. 1986. Contemporary Theories of Knowledge (Rowman and Littlefield).

Pollock, John, and Anthony Gillies. 2000. "Belief Revision and Epistemology." Synthese 122: 69-92. https://doi.org/10.1023/A:1005220010407

Riggs, Wayne D. 2003. “Balancing Our Epistemic Goals.” Nous 37: 342-352. https://doi.org/10.1111/1468-0068.00442

Riggs, Wayne D. 2008. "Epistemic Risk and Relativism." Acta Analytica 23: 1-8. https://doi.org/10.1007/s12136-008-0020-6

Rowe, William. 1979. "The Problem of Evil and Some Varieties of Atheism." American Philosophical Quarterly 16: 335-341.

Rowe, William. 1996. "The Evidential Argument from Evil: A Second Look." In The Evidential Argument from Evil, edited by Daniel Howard-Snyder (Indiana University Press), 262-285.

Rutledge, Jonathan Curtis. 2017. "Commonsense, Skeptical Theism, and Different Sorts of Closure of Inquiry Defeat." Faith and Philosophy 34: 17-32. https://doi.org/10.5840/faithphil201712576

Rutledge, Jonathan Curtis. 2018. "Original Sin, the Fall, and Epistemic Self-Trust." TheoLogica: An International Journal for Philosophy of Religion and Philosophical Theology 2, no. 1. https://doi.org/10.14428/thl.v0i0.1303

Van Inwagen, Peter. 1991. "The Problem of Evil, the Problem of Air, and the Problem of Silence." In Philosophical Perspectives 5: Philosophy of Religion, edited by J. Tomberlin (Ridgeview), 135-165. https://doi.org/10.2307/2214093

Van Inwagen, Peter. 2006. The Problem of Evil (Oxford University Press). https://doi.org/10.1093/acprof:oso/9780199245604.001.0001

Wielenberg, Erik. 2014. “Divine Deception.” In Skeptical Theism: New Essays, edited by Trent Dougherty and Justin P. McBrayer (Oxford University Press), 236-249. https://doi.org/10.1093/acprof:oso/9780199661183.003.0017

Wilks, Ian. 2013. "The Global Skepticism Objection to Skeptical Theism." In The Blackwell Companion to the Problem of Evil, edited by Justin P. McBrayer and Daniel Howard-Snyder (John Wiley and Sons), 458-467.

https://doi.org/10.1002/9781118608005.ch31

Williamson, Timothy. 2000. Knowledge and Its Limits (Oxford University Press). 
Wykstra, Stephen. 1984. "The Humean Obstacle to Evidential Arguments from Suffering: On Avoiding the Evils of 'Appearance.'” International Journal of Philosophy of Religion 16: 73-93. https://doi.org/10.1007/BF00136567

Zagzebski, Linda T. 2012. Epistemic Authority: A Theory of Trust, Authority, and Autonomy in Belief (Oxford University Press).

https://doi.org/10.1093/acprof:oso/9780199936472.001.0001 